Article

\title{
Improved Assessment of Energy Recovery Potential in Water Supply Systems with High Demand Variation
}

\author{
Laura Monteiro * (D), João Delgado and Dídia I. C. Covas (iD \\ CERIS, Instituto Superior Técnico, Universidade de Lisboa, 1049-001 Lisbon, Portugal; \\ joao.borga.delgado@tecnico.ulisboa.pt (J.D.); didia.covas@tecnico.ulisboa.pt (D.I.C.C.) \\ * Correspondence: laura.monteiro@tecnico.ulisboa.pt; Tel.: +351-218-418-145
}

Received: 31 March 2018; Accepted: 11 June 2018; Published: 13 June 2018

\begin{abstract}
Enhancing energy efficiency of water supply systems by recovering part of the excessive pressure is currently an issue of growing interest for water companies. The installation of micro hydro plants for energy recovery can be profitable in sites with excessive pressure, though requiring proper technical and economical evaluation. This paper presents a methodology for assessing the energy recovery potential in water supply systems under high seasonal demand variation. The methodology is based on the calculation of head and flow rate conditions that maximize energy production for a specific energy recovery technology, given available head and flow rate ranges. The methodology is applied to the inlet of a storage tank of a water transmission system using hourly collected data over one year. Results show that, in systems of high variability of flow rate, the installation of turbomachines in parallel is necessary for maximizing energy recovery and that the developed methodology returns lower, but more realistic, energy production estimates than other approaches based on average head and flow rate data.
\end{abstract}

Keywords: energy recovery; assessment methodology; energy efficiency; water transmission systems

\section{Introduction}

Drinking water transport from the source to the consumer is a highly energy intensive process [1], with significant associated operational costs. Water utilities are currently aware of the need for reducing energy consumption and corresponding costs and are looking for innovative ways to improve energy efficiency. The latter can be achieved by improving pumps' efficiency, optimizing pump scheduling and changing the pipe system layout [2] as well as by recovering part of the excessive energy [3,4].

In water systems supplied by gravity, water often carries more energy than what is actually needed to supply the downstream consumers. In such cases, the excessive pressure is dissipated in pressure reducing valves or flow control valves. The installation of micro hydropower plants in parallel with these valves allows the simultaneous recovery of energy and pressure reduction [5]. This strategy can be an economical option by simultaneously controlling pressure, reducing water losses and producing energy [6].

The assessment of the energy recovery potential of a water supply systems requires the identification of the sites where energy is dissipated, the estimation of available hydraulic power and the evaluation of all technical and economic constraints $[5,7,8]$. In this assessment, many uncertainties arise, such as long-term water demand, diurnal and seasonal flow variations and turbines efficiency variation [9]. In addition, the economic feasibility of the project depends on an accurate estimation of costs and on electricity tariff, which is likely to change over the life span of the micro-hydropower plant [10]. Hence, the assessment of the existing potential for energy recovery in water supply systems 
is quite challenging. For the prediction of the energy recovery potential, the identification of the most suitable turbomachine and the prediction of its performance given the available head and flow rate values are key-steps [11].

Among several micro-hydropower turbines [12], pumps operating as turbines (PAT) are pointed as a cost-effective solution for energy recovery in water supply systems $[13,14]$. These hydraulic machines have lower initial investments than specifically designed turbines and are suitable for micro hydropower plants $(<100 \mathrm{~kW})$ with considerable efficiency [3].

This paper aims at presenting and applying a methodology for an improved assessment of the energy recovery potential in water supply systems under high seasonal demand variation. The methodology is based on the calculation of head and flow rate conditions that maximize energy production for a specific energy recovery technology, given the available head and flow rate values over one year. In addition, it aims at improving the estimation of the energy recovery potential of a previously identified location in a real water transmission system, characterized by a high seasonal flow rate variation, considering that the PAT is the chosen technology. Lastly, the paper aims at assessing the feasibility of installing more than one PAT running in parallel to maximize energy recovery.

\section{Enhanced Methodology for Estimating Energy Recovery Potential}

The proposed methodology is composed of four main steps: (i) preliminary assessment; (ii) selection of the turbomachine and establishment of the turbine flow rate range; (iii) estimation of the best efficiency point flow rate and head values and (iv) cost-benefit analysis. These steps are described in the following sections.

\subsection{Preliminary Assessment}

The preliminary assessment of available hydraulic power based on average flow rate and head values should be carried out at all sites in which flow or pressure control valves are installed in order to identify the potential locations for the installation of energy recovery devices. For this purpose, the hydraulic power (Equation (1)) and energy production (Equation (2)) should be estimated for all locations.

$$
\begin{aligned}
& \mathrm{P}_{\mathrm{h}}=\gamma \mathrm{QH} \\
& \mathrm{E}=\eta \mathrm{P}_{\mathrm{h}} \Delta \mathrm{t}
\end{aligned}
$$

where $P_{h}$ is the hydraulic power $(W), \gamma$ is the water specific weigh $\left(N / m^{3}\right), H$ is the available head $(m)$, $Q$ is the flow-rate $\left(\mathrm{m}^{3} / \mathrm{s}\right), E$ is the produced energy $(\mathrm{kWh}), \eta$ is the equipment total efficiency $(\%)$ and $\Delta \mathrm{t}$ is operating time (h) in the period of analysis.

The valve locations with higher potential of energy recovery should be further analyzed in the subsequent steps.

\subsection{Selection of the Turbomachine and Establishment of the Turbine Flow Rate Range}

The average head, flow rate and available hydraulic power allow the identification of the adequate types of turbomachines for the micro-hydropower plant [15]. Pelton turbines are more adequate for high available head values $(>200 \mathrm{~m})$, Kaplan and axial turbines for low head values $(<20 \mathrm{~m})$ and large flow rate values, Francis for intermediate cases and pumps operating as turbines for low flow rates and low to medium heads.

After identification of the most adequate type of machine, the range of operating flow rate values in the turbine should be established in order not to compromise the operating conditions of the turbomachine nor the global efficiency of the machine and the generator. For instance, Kaplan and Pelton turbines can operate with flow rate values in the range of $20 \%$ to $100 \%$ of the best efficiency point flow rate $\left(\mathrm{Q}_{\mathrm{BEP}}\right)$ and Francis turbines between $60-100 \%$, whereas axial fixed-blade turbines and PAT with no frequency variations operate in much smaller ranges [11]. 


\subsection{Estimation of the Best Efficiency Point Flow Rate and Head Values}

The effectively recoverable head by the turbine can be estimated using typical performance curves of the turbomachines provided by manufacturers. If not available, published dimensionless head-flow, efficiency-flow and power-flow curves of similar machines can be used. Head-flow curves typically describe dimensionless head values $\mathrm{H} / \mathrm{H}_{\mathrm{BEP}}$ as a function of $\mathrm{Q} / \mathrm{Q}_{\mathrm{BEP}}$, where $\mathrm{H}$ and $\mathrm{Q}$ are the head and the flow rate, respectively, and $\mathrm{H}_{\mathrm{BEP}}$ and $\mathrm{Q}_{\mathrm{BEP}}$ are the head and the flow rate at the best efficiency point, respectively.

In this step, $\mathrm{Q} / \mathrm{Q}_{\mathrm{BEP}}$ is computed based on time series of flow rate at the site. An initial value for $\mathrm{Q}_{\mathrm{BEP}}$ is given to start the iterative calculation. The ratio $\mathrm{H} / \mathrm{H}_{\mathrm{BEP}}$ is then calculated using $\mathrm{Q} / \mathrm{Q}_{\mathrm{BEP}}$ and the dimensionless head-flow curve. The effectively recoverable head is computed by multiplying $\mathrm{H} / \mathrm{H}_{\mathrm{BEP}}$ by the best efficiency point head. The corresponding recoverable hydraulic power and produced energy are estimated by using Equations (1) and (2). If power-flow curves are available, power can be directly computed without calculating head.

Flow rate and head at the best efficiency point $\left(\mathrm{Q}_{\mathrm{BEP}}, \mathrm{H}_{\mathrm{BEP}}\right)$ are calculated, in an iterative way, using a simple optimization procedure available in Microsoft Excel ${ }^{\circledR}$ (solver function) in order to maximize the total energy recovered in one year.

\subsection{Cost-Benefit Analysis}

Capital costs must be estimated for the economic analysis of the project. Those include the costs of the electro-mechanical equipment, the turbomachine and the civil works. Equipment costs are frequently estimated as a function of the installed power while civil works can be estimated as a percentage of the equipment costs [16]. Cost functions for specific energy recovery technologies can be found in literature [17].

The benefit of the project is a direct function of the electricity generated. For the utilities that to sell the produced energy to the electric grid, the benefit can be calculated by multiplying the amount of annual energy recovered by its selling price $(€ / \mathrm{kWh})$ which may include eventual feed-in tariffs. For those who will consume the produced energy, the benefit comes from the savings in the electricity bill. Thus, the benefit is calculated by multiplying the produced energy by the electricity unit cost. To evaluate the economic feasibility of the project, the Net Present Value (NPV) of the investment is calculated by Equation (3).

$$
\mathrm{NPV}=\sum\left[\mathrm{R}_{\mathrm{t}} /(1+\mathrm{i})^{\mathrm{t}}\right]
$$

where $R$ is the net cash flow at a given time $t, i$ is the discount rate and $t$ is the number of years. The payback period is the value of $t$ that turns NPV into a positive value.

\section{Case Study Characterization}

In a preliminary study, the potential for energy recovery in a Portuguese water supply system was assessed and analyzed [18]. The following approach was based on average monthly head and flow rate data, despite the water demand greatly varying from winter to summer seasons due to the system's location in a touristic area in the south of Portugal (Algarve). Three locations were identified as feasible for the installation of energy recovery solutions (see locations PA, RIV and Q in Figure 1). These sites correspond to the inlet of storage tanks supplied by gravity. Given the high seasonal demand variation, a more accurate feasibility analysis is necessary for estimating the effective energy recovery potential. 


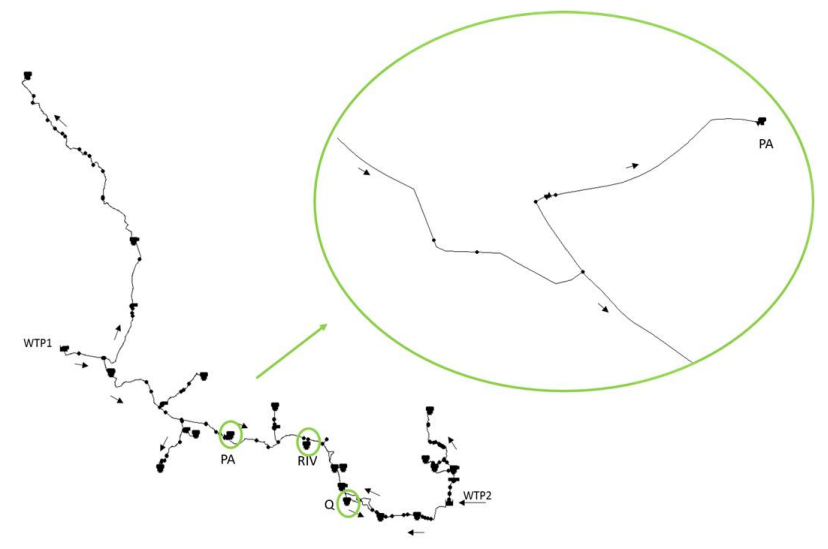

Figure 1. Water transmission system layout, identification of the three identified sites for energy recovery and detail of the location with highest potential.

The proposed methodology will be further applied to assess the energy recovery potential in the most favorable site (PA). Time histories of flow rate and pressure data collected at the inlet of the PA storage tank over one year are used for a more detailed analysis (Figure 2). The chosen year reflects the typical behavior of flow rate and pressure variation in the system. Flow rate data were collected on an hourly basis, while pressure was registered only on a daily basis. This low measurement frequency of pressure is due to the pressure variation being hardly noticeable during the day, which is typical of water transmission systems; relevant pressure variations in this system are only associated to significant increases of flow rate (see pressure-head variation in one year in Figure 2b).

Collected data show that the flow rate increases by a factor of approximately five from winter to summer, as hourly average flow rate at the inlet of the tank ranges from c.a. $50 \mathrm{~L} / \mathrm{s}$ in January to $250 \mathrm{~L} / \mathrm{s}$ in August (Figure 2a). The flow rate duration curve (Figure 3a) indicates that there are no predominant values and that the flow rate is higher than $100 \mathrm{~L} / \mathrm{s}$ more than $50 \%$ of the time. Such variability must be taken into account when estimating the effectively recoverable energy.

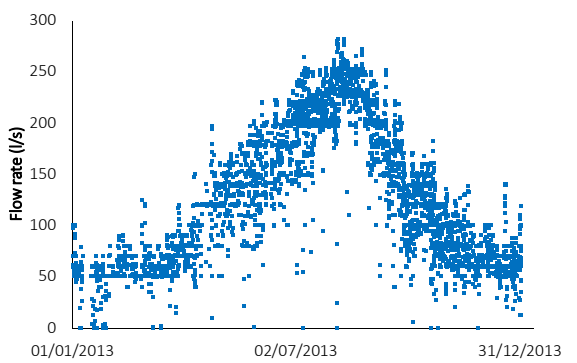

(a)

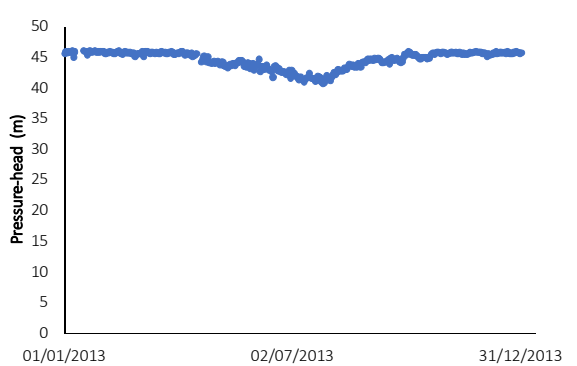

(b)

Figure 2. Historical data of (a) flow rate and (b) pressure-head over one year at the identified location for energy recovery (PA).

Contrarily, pressure only varies from 41 to $46 \mathrm{~m}$ throughout the year (Figure 2b) and remains constant at approximately $46 \mathrm{~m}$ through c.a. $50 \%$ of the time (Figure $3 \mathrm{~b}$ ). As expected, the pressure varies opposite to the flow rate, as it reaches maximum values $(46 \mathrm{~m})$ in winter when the flow rate is minimum and minimum values $(41 \mathrm{~m})$ in summer (Figures 2 and 3c). This suggests that a constant available head of at least $41 \mathrm{~m}$ is available throughout the year.

Comparison of pressure-head variation with flow rate suggests two different operating modes of the system over the year (Figure 3c), which is in agreement with the switching on and off a reversible pumping station installed in the system. 


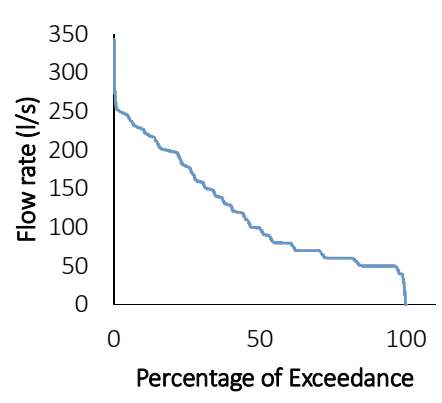

(a)

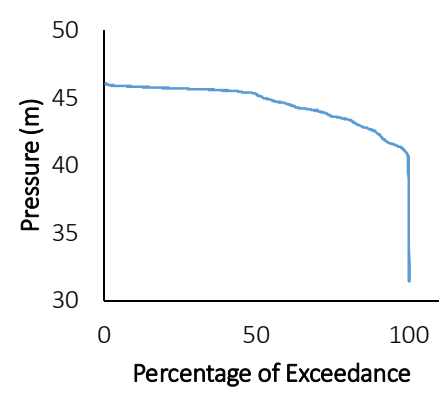

(b)

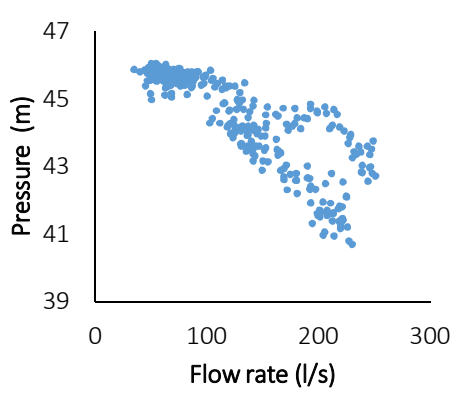

(c)

Figure 3. Annual duration curves of (a) the flow rate and (b) the pressure head. (c) Daily average pressure-head vs. flow rate variation.

\section{Methodology Application to the Case Study}

\subsection{Preliminary Assessment of Available Hydraulic Power}

A preliminary assessment of the energy recovery potential has been carried out for the identified locations and for two seasons (summer and winter) [18]. Available average flow rate values and head values and the corresponding hydraulic powers calculated by Equation (1) are depicted in Figure 4 . These results show that site PA has the highest potential of energy recovery with average hydraulic power values of $30 \mathrm{~kW}$ in winter months (October to April) and of $70 \mathrm{~kW}$ in summer months (May to September). During the year, available hydraulic power in site PA was calculated for each month and varies between 20 and $88.5 \mathrm{~kW}$, with an average of $47 \mathrm{~kW}$. Lower hydraulic powers than the calculated ones are expected, given the high variability of the flow rate.

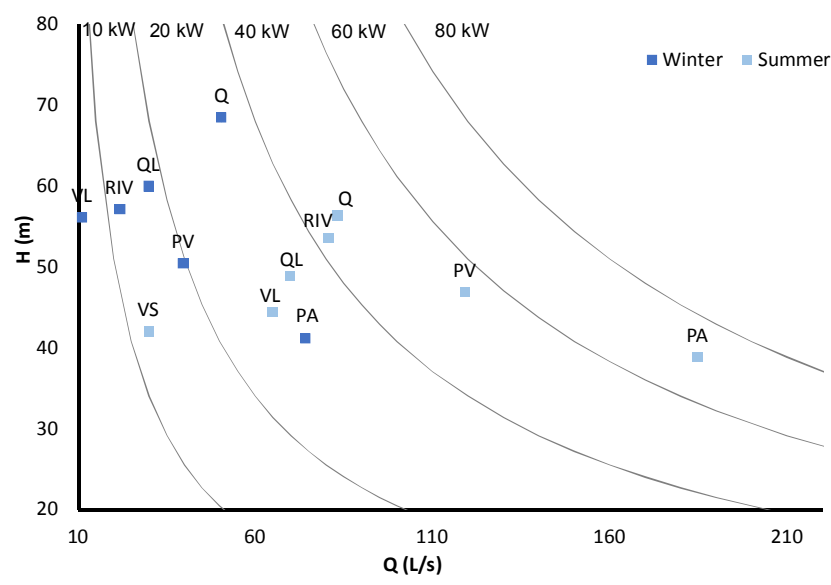

Figure 4. Results from preliminary energy recovery assessment.

\subsection{Selection of the Turbomachine and Establishment of the Turbine Flow Rate Range}

For the range of available flow rate values and head values, the pump running as turbine (PAT) can be a cost-effective solution. This technology will be used herein to illustrate the application of the methodology. In the current case, the flow rate range in the PAT is limited by $80-100 \%$ of $Q_{\text {BEP }}$ [11]. The lower limit aims to guarantee the maximum global efficiency of the machine, whereas the upper limit aims not to compromise the service life of the machine. While an approximate constant efficiency of $70 \%$ can be achieved at the range of 80 to $100 \%$ of $Q_{B E P}$ [11], dangerous unsteady radial forces acting on the components of the PAT can be avoided, as it has been observed in PAT working in full load conditions $[19,20]$. 
However, the high flow variability at the site cannot be accommodated by one single PAT due to its flow rate operating range limitation. Three alternatives were, thus, analyzed, consisting of the installation of one, two and three identical PATs running in parallel, which are switched on and off according to the available flow rate. In this study, PATs operate without frequency variation and the flow rate in the machine is hydraulically regulated by flow control valves installed in a bypass.

\subsection{Estimation of the Best Efficiency Point Flow Rate and Head Values}

For predicting PAT performance, a dimensionless curve (Equation (4)) published in literature was used [21].

$$
\mathrm{H} / \mathrm{H}_{\mathrm{BEP}}=1.0283\left(\mathrm{Q} / \mathrm{Q}_{\mathrm{BEP}}\right)^{2}-0.5468(\mathrm{Q} / \mathrm{QBEP})+0.5314
$$

For the simulation of the simultaneous operation of two and three units in parallel with equally distributed flow rates, two additional curves are computed. These curves describe the global behavior of the PAT, being calculated by multiplying the flow rate $Q$ in Equation (4) by a factor of two (Equation (5)) and three (Equation (6)).

$$
\begin{aligned}
& \mathrm{H} / \mathrm{H}_{\mathrm{BEP}}=0.2571\left(\mathrm{Q} / \mathrm{Q}_{\mathrm{BEP}}\right)^{2}-0.2734\left(\mathrm{Q} / \mathrm{Q}_{\mathrm{BEP}}\right)+0.5314 \\
& \mathrm{H} / \mathrm{H}_{\mathrm{BEP}}=0.1143\left(\mathrm{Q} / \mathrm{Q}_{\mathrm{BEP}}\right)^{2}-0.1823\left(\mathrm{Q} / \mathrm{Q}_{\mathrm{BEP}}\right)+0.5314
\end{aligned}
$$

The obtained curves, plotted in Figure 5, allow the estimation of dimensionless recoverable head, $\mathrm{H} / \mathrm{H}_{\mathrm{BEP}}$, for the operating flow rate, $\mathrm{Q} / \mathrm{Q}_{\mathrm{BEP}}$. The recoverable head $\mathrm{H}$ is calculated by multiplying $\mathrm{H} / \mathrm{H}_{\mathrm{BEP}}$ by the best efficiency point head. A constant value of pressure-head equal to the daily average is used for each hour of the day, since this parameter was not measured in an hourly basis. A minimum backpressure of $5 \mathrm{~m}$ was considered in the analysis.

The estimated PAT operating range for the established flow restrictions is depicted in Figure 5.

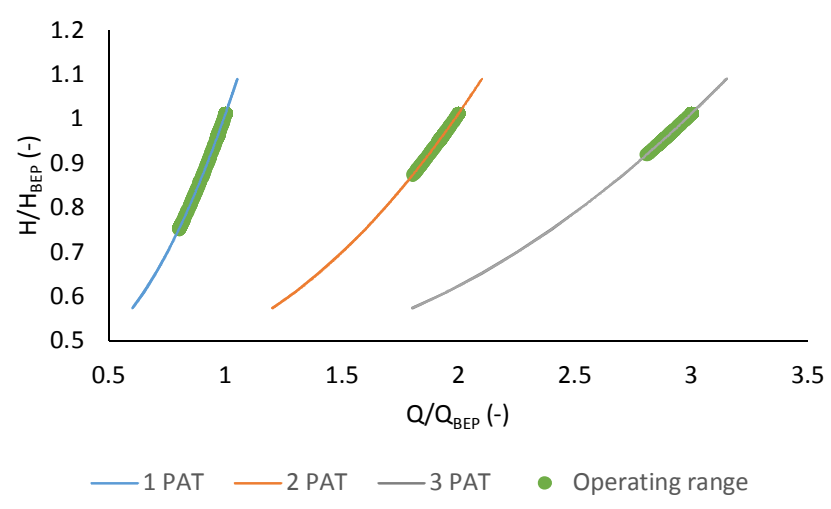

Figure 5. Dimensionless performance curves for one, two and three PAT running in parallel.

Flow rate and head at the best efficiency point $\left(\mathrm{Q}_{\mathrm{BEP}}, \mathrm{H}_{\mathrm{BEP}}\right)$ are calculated by an optimization procedure for the three alternatives aiming at the maximization of the total recovered energy. Estimated best efficiency point flow rate $\left(\mathrm{Q}_{\mathrm{BEP}}\right)$ is $149 \mathrm{~L} / \mathrm{s}$ if only one PAT is installed, $81 \mathrm{~L} / \mathrm{s}$ if two PATs run in parallel and $62 \mathrm{~L} / \mathrm{s}$ if three PATs are installed. The best efficiency point head is $36 \mathrm{~m}$, considering the minimum available pressure-head over the year $(41 \mathrm{~m})$ and minimum backpressure of $5 \mathrm{~m}$. As expected, given the high variability of flow rate at the site and the small operating range of the PAT solution, one single unit can only recover a small part of the available flow (Figure 6a). By increasing the number of PATs, the range of turbined flow increases (Figure $6 b, c$ ). 


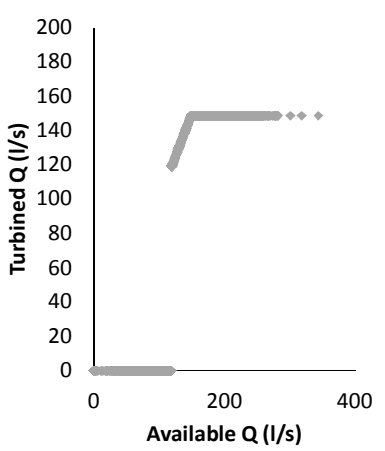

(a)

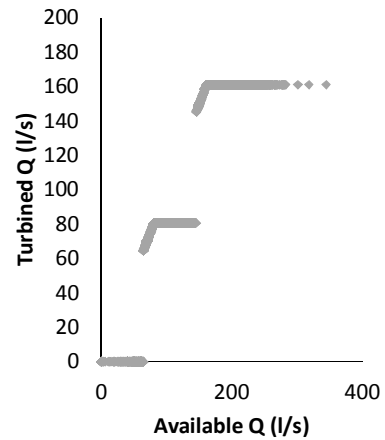

(b)

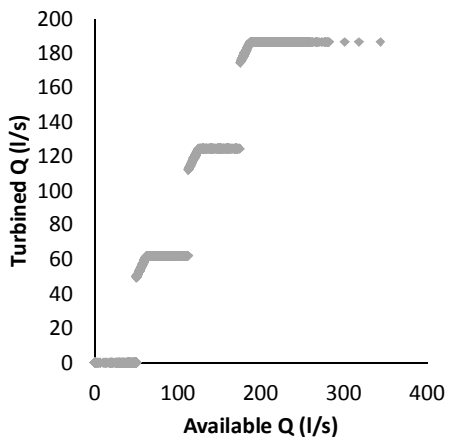

(c)

Figure 6. Turbined flow rate vs. the available flow rate at the site for (a) one PAT, (b) two PATs and (c) three PATs installed in parallel.

\subsection{Energy Recovery Potential}

For the best efficiency point values, recovered energy computed for each hour of the year is presented in Figure 7. Results show that one PAT, designed for maximizing energy recovery, can only effectively recover energy during approximately half of the year (summer) and does not operate on the other half (Figures 7a and 8). Installing two or three PATs in parallel enhances the recovery of the available energy (Figure $7 b, c$ ) as the energy produced increases by $33 \%$ and $62 \%$ if two or three PATs are installed, respectively (Table 1). The number of operating hours of the micro hydropower plant also increases, enabling electricity production all over the year if three PATs run in parallel (Figure 8). This may be an important issue if the energy recovered is to be used for the electric supply of installed equipment, for instance, a monitoring device in a remote location. In this case study, only the set of three PATs will enable energy production throughout the year, despite an energy storage device being necessary for non-operating periods. The decision on whether to install one, two or three PATs requires an economic analysis for each alternative.

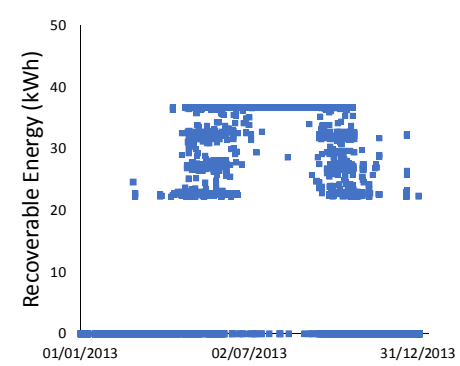

(a)

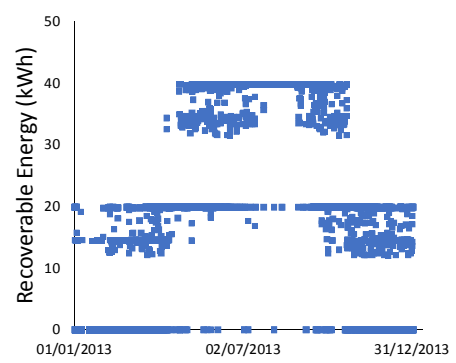

(b)

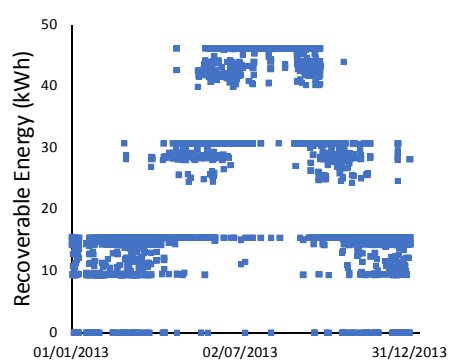

(c)

Figure 7. Daily recoverable energy if (a) one PAT; (b) two PAT and (c) three PAT are installed in parallel.

Table 1. Optimal operating head and flow, produced power and expected annual energy production.

\begin{tabular}{|c|c|c|c|c|c|c|c|c|}
\hline \#PAT & $\begin{array}{c}\mathrm{Q}_{\text {BEP }}(*) \\
(\mathrm{L} / \mathrm{s})\end{array}$ & $\begin{array}{c}\mathrm{H}_{\text {BEP }}\left(^{*}\right) \\
(\mathrm{m})\end{array}$ & $\begin{array}{l}\text { Power } \\
\text { per Unit } \\
(*)(k W)\end{array}$ & $\begin{array}{c}\text { Total } \\
\text { Installed } \\
\text { Power }(k W)\end{array}$ & $\begin{array}{c}\text { Produced } \\
\text { Energy } \\
\text { (kWh/Year) }\end{array}$ & $\begin{array}{c}\text { Capital } \\
\text { Costs }(€)\end{array}$ & $\begin{array}{l}\text { 10-Year } \\
\text { NPV (€) }\end{array}$ & $\begin{array}{c}\text { Payback } \\
\text { Period } \\
\text { (Years) }\end{array}$ \\
\hline Preliminary assessment & 120 & 40 & 47 & 47 & 257,169 & 91,650 & 117,926 & 4 \\
\hline 1 & 149 & 36 & 37 & 37 & 113,586 & 72,150 & 20,415 & 8 \\
\hline 2 & 81 & 36 & 20 & 40 & 151,180 & 78,000 & 21,800 & 8 \\
\hline 3 & 61 & 36 & 15 & 45 & 183,787 & 87,750 & 15,311 & 9 \\
\hline
\end{tabular}

${ }^{*}$ ) In the preliminary assessment these values refer to annual average. 


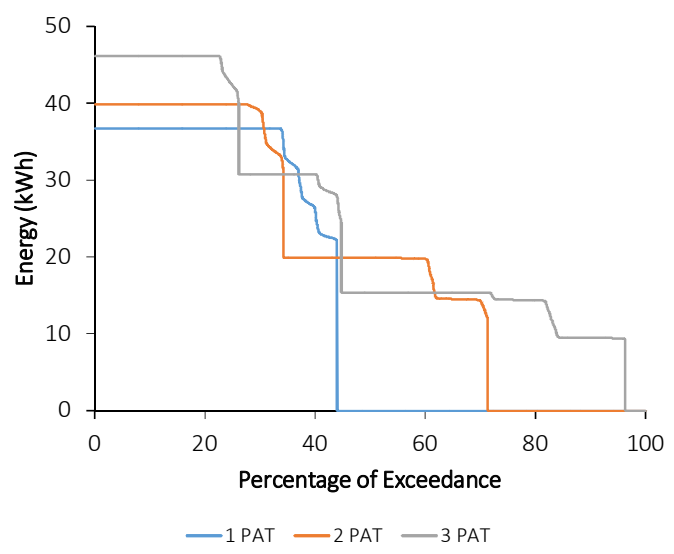

Figure 8. Energy production duration curve for one, two and three PAT installed in parallel.

Results obtained indicate that the yearly recoverable energy at the studied location is of 113, 154 and $186 \mathrm{MWh}$ if one, two or three PATs are installed in parallel, respectively. Comparing with the energy recovery estimate of $257 \mathrm{MWh}$ obtained in the preliminary assessment [18], these values are, as expected, significantly lower (only $44 \%, 59 \%$ and $71 \%$ of the latter, respectively). This result is the consequence of a more detailed energy recovery assessment that takes into account the performance of the device under varying head and flow rate conditions. The incorporation of the behavior of the turbine performance in the energy analysis reflects more closely the real operating conditions for energy recovery in a water supply system with high variability of flow rate, than other approaches based on average monthly data. The use of average values of pressure and flow rate clearly overestimated energy production.

Hence, the developed methodology for assessing the energy recovery potential is necessary, particularly in systems where flow rate significantly varies over time, though it should be noted that results are sensitive to the selected non-dimensional performance curves.

The methodology also allowed us to identify the optimal rated conditions of the PAT to be installed. However, there is no guarantee that these rated conditions are met by existing pumps. Therefore, further research work could be performed regarding the simulation of energy recovery with the characteristic curves of existing PAT with similar rated conditions (i.e., a PAT with similar specific speed). Moreover, this research considered a constant efficiency of $70 \%$. The methodology could be further improved by incorporating the relationship between available hydraulic power and outputted generating power of the selected turbine.

\subsection{Cost-Benefit Analysis}

A cost analysis was carried out for three alternatives (one, two or three PATs installed in parallel). Equipment cost was estimated as a function of the total installed power by considering $1500 € / \mathrm{kW}$ as in [22], though equipment control costs are expected to increase with the number of PAT. Civil works were estimated as $30 \%$ of the equipment cost [22]. Maintenance costs were not considered in this analysis. Produced energy would be used for feeding other electric equipment and hence the economic benefit would correspond to the real energy cost for the utility, that is approximately $0.10 € / \mathrm{kWh}$. The payback period of the investment was calculated at a discount rate of $4 \%$. The Net Present Value (NPV) was calculated for a 10 -year period.

The cost analysis carried out indicates that the payback periods for the studied alternatives are quite similar and are in the range of eight to nine years (Table 1). However, the 10-year Net Present Value is significantly higher when installing one or two PATs than when installing three PATs in parallel. Thus, although the solution of running three PATs does recover more energy, this investment option is less profitable in ten years. 


\section{Conclusions}

An enhanced methodology for assessing the energy recovery potential of water supply systems under high seasonal flow rate variations was developed. It is based on hourly calculation of head and flow rate and estimation of the turbine performance. The methodology includes the estimation of the best efficiency point head and flow rate conditions for maximum energy production.

The methodology was applied to the inlet of a storage tank of a water transmission system and allowed a more realistic assessment of the effectively recoverable power. Results show that, if PAT technology is chosen, the available head and flow rate are not fully recovered by a single unit nor by a set of three PATs running in parallel, although the latter solution allows the production of energy throughout all the year.

In systems of high variability of flows, such as the one studied herein, the use of average values of flow rate and available head allows the identification of potential locations for energy recovery in water supply systems, though a more detailed assessment is necessary. In such systems, the developed methodology returns lower, but more realistic, energy production estimates than other approaches based on monthly head and flow data.

Author Contributions: Conceptualization, Methodology development and Supervision by D.I.C.C. Formal analysis and investigation was carried out by L.M. The Writing-Review \& Editing was accomplished by L.M., J.D. and D.I.C.C. D.I.C.C. was also responsible for funding acquisition.

Funding: This research was funded by the European Commission's LIFE Programme through LIFE SWSS project grant number LIFE14 ENV/PT/000508.

Acknowledgments: The authors acknowledge Águas do Algarve S.A. for providing data.

Conflicts of Interest: The authors declare no conflict of interest. The founding sponsors had no role in the design of the study; in the collection, analyses, or interpretation of data; in the writing of the manuscript, and in the decision to publish the results.

\section{References}

1. Lofman, D.; Petersen, M.; Bower, A. Water, Energy and Environment Nexus: The California Experience. Int. J. Water Resour. Dev. 2002, 18, 73-85. [CrossRef]

2. Mamade, A.; Loureiro, D.; Alegre, H.; Covas, D. A comprehensive and well tested energy balance for water supply systems. Urban Water J. 2017, 14, 853-861. [CrossRef]

3. Williams, A.A.; Smith, N.P.A.; Bird, C.; Howard, M. Pumps as Turbines and Induction Motors as Generators for Energy Recovery in Water Supply Systems. Water Environ. J. 1998, 12, 175-178. [CrossRef]

4. Fecarotta, O.; McNabola, A. Optimal Location of Pump as Turbines (PATs) in Water Distribution Networks to Recover Energy and Reduce Leakage. Water Resour. Manag. 2017, 31, 5043-5059. [CrossRef]

5. Gallagher, J.; Harris, I.M.; Packwood, A.J.; McNabola, A.; Williams, A.P. A strategic assessment of micro-hydropower in the UK and Irish water industry: Identifying technical and economic constraints. Renew. Energy 2015, 81, 808-815. [CrossRef]

6. Ulanicki, B.; Bounds, P.L.M.; Rance, J.P.; Reynolds, L. Open and closed loop pressure control for leakage reduction. Urb. Water 2000, 2, 105-114. [CrossRef]

7. McNabola, A.; Coughlan, P.; Williams, A.P. Energy recovery in the water industry: An assessment of the potential of micro-hydropower. Water Environ. J. 2014, 28, 294-304. [CrossRef]

8. Su, P.-A.; Karney, B. Micro hydroelectric energy recovery in municipal water systems: A case study for Vancouver. Urb. Water J. 2015, 12, 678-690. [CrossRef]

9. Corcoran, L.; McNabola, A.; Coughlan, P. Predicting and quantifying the effect of variations in long-term water demand on micro-hydropower energy recovery in water supply networks. Urb. Water J. 2016, 1-9. [CrossRef]

10. Corcoran, L.; Coughlan, P.; McNabola, A. Energy recovery potential using micro hydropower in water supply networks in the UK and Ireland. Water Sci. Technol. Water Supply 2013, 13, 552-560. [CrossRef]

11. Jain, S.V.; Patel, R.N. Investigations on pump running in turbine mode: A review of the state-of-the-art. Renew. Sustain. Energy Rev. 2014, 30, 841-868. [CrossRef] 
12. Jawahar, C.P.; Michael, P.A. A review on turbines for micro hydro power plant. Renew. Sustain. Energy Rev. 2017, 72, 882-887. [CrossRef]

13. Carravetta, A.; Derakhshan Houreh, S.; Ramos, H.M. Pumps as Turbines Fundamentals and Applications, 1st ed.; Springer International Publishing: Cham, Switzerland, 2018, ISBN 978-3-319-67506-0.

14. Carravetta, A.; Del Giudice, G.; Fecarotta, O.; Ramos, M.H. Pump as Turbine (PAT) Design in Water Distribution Network by System Effectiveness. Water 2013, 5, 1211. [CrossRef]

15. ESHA. Layman's Guidebook on How to Develop a Small Hydro Site, 2nd ed.; European Small Hydropower Association: Brussels, Belgium, 1998.

16. Aggidis, G.A.; Luchinskaya, E.; Rothschild, R.; Howard, D.C. The costs of small-scale hydro power production: Impact on the development of existing potential. Renew. Energy 2010, 35, 2632-2638. [CrossRef]

17. Ogayar, B.; Vidal, P.G. Cost determination of the electro-mechanical equipment of a small hydro-power plant. Renew. Energy 2009, 34, 6-13. [CrossRef]

18. Monteiro, L.; Delgado, J.; Figueiredo, D.; Alves, R.; Póvoa, P.; Covas, D.I.C. Assessment of the potential for energy recovery in water trunk mains. In Proceedings of the 14th Computing and Control for the Water Industry Conference, Amsterdam, The Netherlands, 7-9 November 2016.

19. Santolaria Morros, C.; Fernández Oro, J.M.; Argüelles Díaz, K.M. Numerical modelling and flow analysis of a centrifugal pump running as a turbine: Unsteady flow structures and its effects on the global performance. Int. J. Numer. Methods Fluids 2011, 65, 542-562. [CrossRef]

20. Fernández, J.; Barrio, R.; Blanco, E.; Parrondo, J.; Marcos, A. Experimental and Numerical Investigation of a Centrifugal Pump Working as a Turbine. In Proceedings of the ASME 2009 Fluids Engineering Division Summer Meeting, Vail, CO, USA, 2-6 August 2009; pp. 471-479. [CrossRef]

21. Derakhshan, S.; Nourbakhsh, A. Experimental study of characteristic curves of centrifugal pumps working as turbines in different specific speeds. Exp. Therm. Fluid Sci. 2008, 32, 800-807. [CrossRef]

22. Fontana, N.; Giugni, M.; Portolano, D. Losses Reduction and Energy Production in Water-Distribution Networks. J. Water Resour. Plan. Manag. 2012, 138, 237-244. [CrossRef]

(C) 2018 by the authors. Licensee MDPI, Basel, Switzerland. This article is an open access article distributed under the terms and conditions of the Creative Commons Attribution (CC BY) license (http:/ / creativecommons.org/licenses/by/4.0/). 